\title{
Racial inequities in tooth loss among older Brazilian adults: A decomposition analysis
}

Rafael Aiello Bomfim ${ }^{1,5}$, Ione Jayce Ceola Schneider ${ }^{2,3}$, Fabiola Bof de Andrade ${ }^{4}$, Maria Fernanda Lima-Costa ${ }^{4}$, Vanessa Pereira Corrêa ${ }^{3}$, Paulo Frazão ${ }^{5}$, Richard Watt ${ }^{2}$, João Luiz Bastos $^{6}$, Cesar de Oliveira ${ }^{2}$

Author 1 RAB: Contributed to conception, design, data analysis and interpretation, performed all statistical analyses, drafted and critically revised the manuscript

Author 2 IJCS: Contributed to conception, design, data analysis and interpretation, drafted and critically revised the manuscript

Author 3 MFLC: Contributed to data analysis and interpretation, drafted and critically revised the manuscript

Author 4 FBA: Contributed to data analysis and interpretation, drafted and critically revised the manuscript

Author 5 VPC: Contributed to data analysis and interpretation, drafted and critically revised the manuscript

Author 6 PF: Contributed to data analysis and interpretation, drafted and critically revised the manuscript

Author 7 RGW: Contributed data analysis and interpretation, drafted and critically revised the manuscript

Author 8 JLB: Contributed to data analysis and interpretation, drafted and critically revised the manuscript

Author 9 CO: Contributed to conception, design, data acquisition and analysis and interpretation, drafted and critically revised the manuscript

All authors gave their final approval and agree to be accountable for all aspects of the work.

\section{Affiliations:}

${ }^{1}$ School of Dentistry, Federal University of Mato Grosso do Sul, Campo Grande, Brazil

${ }^{2}$ Department of Epidemiology \& Public Health, University College London, London, UK

${ }^{3}$ Health Science Department and Rehabilitation Post-graduate Program, Federal University of Santa Catarina, Araranguá, Santa Catarina, Brazil

${ }^{4}$ Oswaldo Cruz Foundation, René Rachou Research Institute, Belo Horizonte, Brazil

${ }^{5}$ Public Health School, University of Sao Paulo, Sao Paulo, Brazil

${ }^{6}$ Post-Graduate Program in Public Health, Federal University of Santa Catarina, 
Florianópolis, Santa Catarina, Brazil

*Corresponding author:

Dr Rafael Aiello Bomfim

School of Dentistry, Federal University of Mato Grosso do Sul

Av. Senador Fillinto Muller s/n- Cidade Universitária, CEP:79070-900, Campo Grande, MS, Brasil

Tel +556733457379

Email: aiello.rafael@gmail.com 


\section{Abstract}

Objective: To determine the extent to which racial inequities in tooth loss and functional dentition are explained by individual socioeconomic status, smoking status and frequency/reason for the use of dental services. Methods: Data came from the Brazilian Longitudinal Study of Ageing, a nationally representative sample of community-dwelling people aged 50 years and over. Tooth loss and functional dentition (i.e. $20+$ natural teeth) were the outcomes. The main explanatory variable was self-classified race. Covariates included dental visits in the past 12 months, dental visits for check-ups only, smoking status, self-reported chronic conditions, depression and cognitive function. Logistic regression and Blinder-Oaxaca decomposition analysis were used to estimate the share of each factor in race-related tooth loss inequities. Results: The analytical sample comprised 7,126 respondents. While the prevalence of functional dentition in White Brazilians was $37 \%$ (95\%CI: 33.5;40.9), it was 29\% (95\%CI: 26.4;31.6) among Browns, and 30\% (95\%CI:25.1;35.4) among Blacks. The average number of lost teeth among Whites, Browns and Blacks were 18.7 (95\%CI: 17.8;19.6), 20.4 (95\%CI: 19.7;21.1), and 20.8 (95\%CI: $19.5 ; 22.0)$, respectively. Decomposition analysis showed that $71 \%$ of the racial inequalities in tooth loss were explained by the selected covariates. Dental visits in the previous year and smoking status explained nearly half of race-related gaps. Other factors, such as per capita income, education and cognitive status also had an important contribution to the examined inequalities. The proportion of racial inequities in tooth loss that was explained by dental visits (frequency and reason) and smoking status decreased from $40 \%$ for those $50-59$ years of age to $22 \%$ among participants aged $70-79$ years. Conclusions: Frequency and reason for dental visits and smoking status explained nearly half of the racial inequity in tooth loss among Brazilian older adults. The Brazilian Family Health Strategy program should target older adults from racial groups living in deprived areas.

Keywords: Racial inequity, tooth loss, aging, epidemiology, health inequalities 


\section{Introduction}

Brazil has the world's largest population of African descent outside of the African continent, as well as high levels of racial miscegenation ${ }^{1}$. This reflects a complex and long-standing social process shaped by an interplay of slavery, class, and gender oppression ${ }^{2}$. According to the Brazilian Census Bureau, the racial composition of the population in 2015 was $45.2 \%$ White, $45.1 \%$ Brown, 8.9\% Black, 0.5\% Asian, and 0.4\% Indigenous ${ }^{3}$.

Increasing evidence suggests that racial discrimination is an emerging risk factor for disease and a contributor to racial inequities in health ${ }^{4}$. Although the use of race in biomedical publications is surrounded by much controversy ${ }^{5}$, racial gaps in oral health need to be addressed as far as equity and social justice concerns are to be taken into account. The relative disadvantage that racial minorities face in terms of oral health has recently been interpreted as stemming from structural or macro-level processes, including the lack of oral health services, living in deprived neighbourhoods, and having restricted access to fluoridated piped water ${ }^{6}$. The most recent evidence on the topic is based on the premise that racial health inequities are the result of social, cultural and economic factors, not biological susceptibility ${ }^{4,6}$.

Tooth loss is an important public health problem worldwide, especially among older adults $^{7}$. It presents a challenge to oral health services aimed at improving oral healthrelated quality of life ${ }^{8}$. Tooth loss negatively influences both disability-adjusted life-years (DALYs) and years lived with disability (YLDs) ${ }^{9}$. The most recent nationwide oral epidemiological survey conducted in Brazil revealed high tooth loss levels among older adults, with values as large as an average of 25 teeth lost per person in some specific population subgroups ${ }^{10}$. The World Health Organization (WHO) defines 20 as the minimum number of teeth required for individuals to take part in social activities, as well as achieve an adequate masticatory function - this is commonly referred to as a functional dentition ${ }^{11}$.

Previous accounts on racial inequities in oral health have assumed that excessive levels of chronic morbidity and disability are widespread among Blacks, as well as that early health deterioration results from the cumulative impact of repeated experiences with 
social, economic, and political exclusion ${ }^{12}$. Indeed, oral microbiota may change with systemic diseases ${ }^{13}$, which may contribute to tooth loss. Also, cognitive decline has been associated with tooth $\operatorname{loss}^{14}$ and racial inequities in health ${ }^{15}$. Importantly, tooth loss is associated with smoking through periodontal disease ${ }^{16}$. To estimate the extent to which racial inequities in tooth loss are explained by individual socioeconomic status and healthrelated behaviours is, therefore, warranted. Such information is useful for health services planning and oral health policies aiming to promote racial equity in oral health.

Decomposition analysis is a widely known analytical technique that has been used in dental public health ${ }^{17-21}$ to explain socioeconomic inequalities in oral health outcomes. It emulates a counterfactual analysis that explains changes in mean values of a potential outcome, e.g. tooth loss, when individuals in the dataset are from different racial groups, in this case, White versus Browns and Blacks. It estimates the relative contribution of each predictor to racial inequities in a specified outcome, as well as potential differences among factors that are taken into consideration. To the best of our knowledge, this is the first study to use decomposition analysis to explain racial inequities in tooth loss in a nationally representative sample of community-dwelling older Brazilian adults aged 50 and over.

\section{Methods}

\section{Study population}

The Brazilian Longitudinal Study of Ageing (ELSI-Brazil) is a large population-based cohort study, designed to represent the Brazilian population aged 50 years and over. The main objective of the study is to investigate the dynamics of ageing in the Brazilian population, as well as its determinants. The baseline data collection took place in 201516; further details can be found elsewhere ${ }^{22}$. The ELSI-Brazil baseline data collection included: 1) a household interview; 2) an individual interview with the selected participants; 3) physical measurements; 4) laboratory tests; and 5) storage of blood samples for future analyses. Individual variables were collected through face-to-face interviews, conducted with a structured questionnaire at the participants' homes. The Fiocruz Research Ethics Committee, Minas Gerais (CAAE 34649814.3.0000.5091), approved the ELSI-Brazil study protocol. All participants signed separate informed 
consent forms for each of the research procedures.

\section{Exclusion criteria}

Due to small numbers within the ELSI-Brazil sample, Indigenous and Asian participants ( $2 \%$ and $1 \%$, respectively) were not included in the present analysis.

\section{Outcomes}

The following two oral health outcomes were analysed in the present study: the presence of functional dentition yes (0) and no (1) and self-reported tooth loss, estimated by the subtraction of the total number of teeth in the upper and lower dental arches from the maximum number of natural teeth in the human dentition, i.e. 32 .

\section{Racial classification}

Self-reported race was based on the classification of the Brazilian Institute for Geography and Statistics (IBGE) $)^{3}$, which includes Whites, Browns and Blacks,

\section{Covariates}

Covariates were gender (men or women), age (divided into groups of 50-59, 60-69, 7079 and 80+), schooling (0,1-4, 4-7, 7-11 and 11+ years of formal education) and income (equivalised per capita income, grouped into tertiles) ${ }^{23}$.

Cognitive function was assessed with the word list-learning test, according to which 10 words are read to participants who are subsequently asked to repeat them at pre-specified time intervals. While immediate memory was defined as the repetition of words mentioned immediately after their reading, late memory (delayed recall) was assessed by their repetition five minutes after the test was initiated. A memory score, later divided into tertiles, was obtained from the sum of answers for immediate and delayed recall ${ }^{24}$. Depressive symptoms were assessed with the 8-item Center for Epidemiologic Studies Depression Scale (CES-D-8) $25-26$. Depressive symptoms were considered present when four or more symptoms were reported ${ }^{25}$. Self-reported hypertension (yes, no) and diabetes 
(yes, no) were also included as covariates in the analysis. Health behaviours included were frequency of dental service use (less than 12 months, between 1 and 2 years, more than 3 years), dental visits for check-up only (yes [dental visits for prevention, check-ups and revision], no [dental visits for pain, extraction, treatment and other reasons, except prevention]), and self-reported smoking status (never smoked, smoked in the past and current smoker). We followed the STROBE guidelines for human observational studies ${ }^{27}$.

\section{Statistical Analysis}

First, we estimated a logistic regression model to estimate the magnitude of racial inequities in functional dentition, adjusted for education, equivalised per capita income, health behaviours and self-reported medical conditions. Associations between race and functional dentition were expressed as Odds Ratios (OR), following assessment of goodness-of-fit criteria through AIC and BIC. We estimated the odds of not having functional dentition. The models were adjusted by socioeconomic status (income and schooling), dental services use and smoking status.

Next, we ran the Blinder-Oaxaca decomposition analysis. This is a counterfactual analysis that explains the change in the mean values of a potential outcome, e.g. tooth loss, when individuals in the dataset are from different racial groups. In our analyses, we had two groups: Whites and Browns/Blacks. This technique also allows for mean differences between the groups to be explained by a set of explanatory variables ${ }^{28,29}$. All coefficients were obtained from the pooled data regression ${ }^{30}$. Analyses were run using Stata $14.2^{31}$, taking into consideration the complex sampling design and the sampling weights. Age groups were also analysed separately to identify potential differences among them in the extent to which covariates explained racial inequities in functional dentition. We specifically estimated the extent to which health behaviours, represented by the frequency of dental service use, dental visits for check-up and smoking status explain the racial inequities in tooth loss.

\section{Results}

The analytical sample comprised 7,126 ELSI-Brazil participants aged 50 years and over who had information on all variables included in the study. Table 1 shows the 
characteristics of these complete cases. The prevalence of functional dentition was higher among Whites than among Browns/Blacks. Unadjusted logistic regression models showed differences in the prevalence of functional dentition between Blacks and Browns than Whites in all age groups. After adjusting for smoking status, frequency and reason for dental visits, and socioeconomic status, the coefficients for the race were higher for Browns than Whites in all age groups, but we did not observe racial inequities between Blacks and Whites.

Table 3 displays the results from the decomposition analysis, adjusted for age. The variables included in the model explained around $70 \%$ of the racial inequity in tooth loss. Racial inequities in tooth loss were explained by the following factors: smoking status (7.0\%), dental visits in the past 12 months (23.3\%), and dental visits for checkup/prevention only (15.5\%). Per capita income, education, and cognitive status explained the remaining variability of the outcome. Not surprisingly, racial inequities in tooth loss between both racial groups were lower with increasing age, since tooth loss increases later in life across all racial groups.

Table 4 shows the decomposition analysis for each of the studied age groups. For the 5059 age group, dental services use in the past 12 months, dental visits for checkup/prevention only, and smoking explained $40 \%$ of the racial inequities in tooth loss, with such estimate decreasing to $30 \%$ in the $60-69$ age group, and $22 \%$ in the $70-79$ age group. Socioeconomic status and cognitive function, on the other hand, showed an increased contribution to the racial inequities in tooth loss among older participants. In the age group from 50-59 years, socioeconomic status (income and schooling) explained 47\% of the racial inequities in tooth loss, increasing to around 60\% in the age groups from 60-69 and 70-79 years. Moreover, tooth loss differences increased from 50-59 years to 60-69 years and then decreased in 70-79 years.

A sensitivity analysis comparing the racial groups separately showed similar results. An additional sensitivity analysis categorizing tooth loss according to groups of natural teeth (edentulous; 1-9 teeth; 10-19 teeth and more than 20 teeth) showed similar findings (Table 3). Appendixes 1 and 2 show the prevalence of functional dentition and mean tooth loss by covariates in the three different racial groups, respectively. Appendix 3 shows the comparative analyses between the individuals included in the study and those excluded 
due to a lack of information on the included covariates. There were no significant differences between the studied racial groups.

\section{Discussion}

This study showed two important findings. First, there were racial inequities in functional dentition among older Brazilian adults, with a poorer profile for Browns than Whites. Second, decomposition analysis indicated that smoking status and frequency/reason for dental visits explained almost half of the racial gaps in tooth loss, especially in the younger age group i.e. 50-59 years.

This study has some strengths and limitations that should be acknowledged. A key strength is the use of a large dataset from the ELSI-Brazil study, a nationally representative sample of people aged 50 years and over. ELSI-Brazil is part of an international network of harmonised ageing studies that includes countries like the US, England, Mexico, China, India, South Africa and others. Self-reported number of teeth could be a potential source of bias. However, there is evidence showing that this is a valid and reliable measure. We do not have access to data at the municipality level, which is important to assess whether and how racism influences access to oral health coverage and oral health policies. It may well be that the unexplained share i.e. $30 \%$ of the racial inequity in tooth loss could be attributable to structural or macro-level factors such as oral health coverage and living in deprived neighbourhoods with no access to fluoridated piped water. Future studies looking into racial inequities in tooth loss should consider such factors.

One of the most important contributions of the present study was to show that the use of dental services and smoking status explained a large proportion of the racial inequity in tooth loss later in life. Data from US adults showed that fewer dental visits and preventive dental visits among non-Whites ${ }^{32}$ remained as significant factors in explaining differences between Asian-Indians and Chinese Americans with neighbourhood having an important contribution in explaining access to dental services ${ }^{33-34}$. Our findings thus highlight the contribution of dental service utilization to racial inequities in tooth loss. This result suggests that the Brazilian Family Health Strategy program should target older adults from racial groups living in deprived areas. The focus could be to minimize racial 
differences in tooth loss among people aged 50-59 years since racial inequities in this group were particularly sensitive to the role of dental service utilization.

Previous studies showed that socioeconomic status plays an important role in racial oral health inequalities in US adults ${ }^{35}$. In Hawaii, for instance, native Hawaiians have an excess tooth loss ${ }^{36}$ compared to Whites, with income and education playing an important role in this association. Among older Brazilian adults, socioeconomic status also plays an important role in tooth loss and functional dentition ${ }^{37,38}$. Moreover, wealthier people are more likely to know the risks and have the resources (money, knowledge, power, prestige, and beneficial social connections) to engage in prevention or treatment ${ }^{39}$.

In our study, decomposition analysis showed that the analysed covariates explained almost $70 \%$ of the racial inequity in tooth loss. In the age group from 50- 59 years, socioeconomic status explained $47 \%$ of the racial inequities in tooth loss, increasing to $56 \%$ in the age group from 60-69 years with similar values for the age group between 70 79 years. Contrary to our expectations, our study showed that $10 \%$ of the racial inequities in tooth loss was attributed to cognitive impairment, measured by delayed word recall. A previous research showed that associations between cognitive decline and tooth loss were attributable, in part, to confounding effects of education and general health status ${ }^{14}$. In our analyses, even after adjustments for education, income and general health (diabetes, hypertension and depression symptoms), a portion of racial inequities in tooth loss remained attributable to cognitive impairment. It could be hypothesized that poorer cognitive function could lead to poorer oral health hygiene attitudes, plaque accumulation and gingivitis ${ }^{14}$ and may contribute to tooth loss. Our study showed that for Whites in the highest tertile (better cognitive function) $43.2 \%$ had the presence of functional dentition, against $35.6 \%$ of Browns and $34.3 \%$ of Blacks. Similarly, for tooth loss, Whites had a mean number of 16.9 lost teeth compared to a mean number of 18.2 for Browns and 19.2 for Blacks (Appendixes 1 and 2). In another study, tooth loss was associated with a greater deficit in cognitive decline, but the number of teeth did not predict greater deficits in cognitive decline $\mathrm{e}^{40}$. In other words, it is not fully understood whether there is a bidirectional association between cognitive decline and tooth loss.

Another hypothesis for differences between Whites and Browns/Blacks refers to racial/ethnic discrimination. Manifestation of negative attitudes, judgments, or 
differential treatment based on ethnicity, race, or skin-color that disadvantages a racial group has emerged as an explanation for the persistence of health inequities in some contexts ${ }^{4,6,39}$. Among the components of racism, and how these factors can affect health, our findings emphasized the role of dental services utilization. Inequities in dental care availability are most pronounced in racial/ethnic minority communities. ${ }^{41}$ Moreover, racial inequities in functional dentition persist among Whites/Browns, even after adjusting for socioeconomic status (SES). This means that not all flexible resources associated with race overlap with SES. Some of these resources, such as income and schooling, are an inherent part of SES, but others, such as neighbourhood conditions (with implications to preventive health behaviours, access to oral health policies, dental service utilization and possible other stressors) ${ }^{39}$ and fluoridated piped water are not ${ }^{6}$. The social and policy importance of a fundamental cause of health inequities lies in the fact that inequities based on race cannot be eliminated by addressing the mechanisms that currently link the SES to health ${ }^{39}$.

Our study confirms the importance to directly address racial inequities. In Brazil, as dental public health services are important for Browns/Blacks ${ }^{42}$, the Family Health Strategy program should target those racial groups living in deprivation. In conclusion, frequency and reason for dental visits and smoking status explained nearly half of the racial inequity in tooth loss among Brazilian older adults. The Brazilian Family Health Strategy program should target older adults from racial groups living in deprivation. 


\section{Acknowledgements}

Rafael Aiello Bomfim received a Brazilian National Research Council (CNPq) scholarship for post-doctoral research, process 153623/2018-7. The author thank the Federal University of Mato Grosso do Sul (UFMS) for the post-doctoral leave and the Brazilian Ministry of Health and Fiocruz (MG) for the research funding. This study was supported by the CNPq, through research grant 304503/2018-5 to João Luiz Bastos.

Author 1 RAB: Contributed to conception, design, data interpretation, performed all statistical analyses, drafted and critically revised the manuscript

Author 2 IJCS: Contributed to conception, design, data interpretation, drafted and critically revised the manuscript

Author 3 MFLC: Contributed to conception, design, data acquisition and interpretation, drafted and critically revised the manuscript

Author 4 FBA: Contributed to conception, design, data acquisition and interpretation, drafted and critically revised the manuscript

Author 5 VPC: Contributed to conception, data interpretation, drafted and critically revised the manuscript

Author 6 PF: Contributed to conception, data acquisition and interpretation, performed all statistical analyses, drafted and critically revised the manuscript

Author 7 RGW: Contributed to conception, data interpretation, drafted and critically revised the manuscript

Author 8 JLB: Contributed to conception, data interpretation, drafted and critically revised the manuscript

Author $9 \mathrm{CO}$ : Contributed to conception, design, data acquisition and interpretation, , drafted and critically revised the manuscript

All authors gave their final approval and agree to be accountable for all aspects of the work.

Conflict of interest: none

More information could be seen at

http://elsi.cpqrr.fiocruz.br/

\section{References}

1. Arteaga JS. Biological Discourses on Human Races and Scientific Racism in Brazil (18321911). J Hist Biol. 2017;50(2):267-314.

2. BonillaSilva E. Rethinking racism: Toward a structural interpretation. Am Sociol Rev. 1997;62(3):465-80.

3. Brazilian Institute Geography and Statistics (IBGE). Brazil 2015. Accessed in July 15th 2019 Available in <https://educa.ibge.gov.br/jovens/conheca-o-brasil/populacao/18319-corou-raca.html>. 
4. Williams DR, Lawrence JA, Davis BA, Vu C. Understanding how discrimination can affect health. Health Serv Res. 2019;54:1374-88.

5. Kaplan JB, Bennett T. Use of race and ethnicity in biomedical publication. JAMA. 2003;289(20):2709-16.

6. Bastos JL, Celeste RK, Paradies YC. Racial Inequalities in Oral Health. J Dent Res. 2018;97(8):878-86.

7. Marcenes W, Kassebaum NJ, Bernabe E, Flaxman A, Naghavi M, Lopez A, et al. Global Burden of Oral Conditions in 1990-2010: A Systematic Analysis. J Dent Res. 2013;92(7):592-7.

8. Watt RG, Daly B, Allison P, Macpherson LMD, Venturelli R, Listl S, et al. Ending the neglect of global oral health: time for radical action. Lancet. 2019;394(10194):261-72.

9. Peres MA, Macpherson LMD, Weyant RJ, Daly B, Venturelli R, Mathur MR, et al. Oral diseases: a global public health challenge. Lancet. 2019;394(10194):249-60.

10. Brazilian Ministry of Health, Oral Health Department. 2012. Política nacional de saúde bucal. Access April 15th 2019. Available in <http://bvsms.saude.gov.br/bvs/publicacoes/pesquisa_nacional_saude_bucal.pdf>

11. Petersen P, Kwan S. The 7(th) WHO Global Conference on Health Promotion - towards integration of oral health (Nairobi, Kenya 2009). Community Dent Health. 2010;27(2):129-36.

12. Geronimus AT. Understanding and eliminating racial inequalities in women's health in the United States: the role of the weathering conceptual framework. J Am Med Womens Assoc (1972). 2001;56(4):133-6, 49-50.

13. Graves DT, Corrêa JD, Silva TA. The Oral Microbiota Is Modified by Systemic Diseases. J Dent Res. 2019;98(2):148-56.

14. Naorungroj S, Slade GD, Beck JD, Mosley TH, Gottesman RF, Alonso A, et al. Cognitive decline and oral health in middle-aged adults in the ARIC study. J Dent Res. 2013;92(9):795-801. 15. Zhang ZM, Hayward MD, Yu YL. Life Course Pathways to Racial Disparities in Cognitive Impairment among Older Americans. J Health Soc Behav. 2016;57(2):184-99.

16. Simila T, Virtanen Jl. Association between smoking intensity and duration and tooth loss among Finnish middle-aged adults: the northern Finland birth cohort 1966 project. BMC Public Health. 2015;15:1141-1148.

17. Peres MA, Ju X, Mittinty M, Spencer AJ, Do LG. Modifiable Factors Explain Socioeconomic Inequalities in Children's Dental Caries. J Dent Res. 2019;98(11):1211-8.

18. Godoi H, Singh A, de Mello A, Brennan DS, Peres MA. Area-level social development and indicators of public dental services in Southern Brazil. Community Dent Oral Epidemiol. 2019;47(3):274-80.

19. Tsakos G, Guarnizo-Herreno CC, O'Connor R, Wildman J, Steele JG, Allen PF. Explaining time changes in oral health-related quality of life in England: a decomposition analysis. $J$ Epidemiol Community Health. 2017;71(12):1203-9.

20. Safiri S, Kelishadi R, Heshmat R, Rahimi A, Djalalinia S, Ghasemian A, et al. Socioeconomic inequality in oral health behavior in Iranian children and adolescents by the Oaxaca-Blinder decomposition method: the CASPIAN-IV study. International Journal for Equity in Health. $2016 ; 15$.

21. Shen J, Listl S. Investigating social inequalities in older adults' dentition and the role of dental service use in 14 European countries. European J Health Econ. 2018;19(1):45-57.

22. Fernanda Lima-Costa M, de Andrade FB, Borges de Souza PR, Jr., Neri AL, de Oliveira Duarte YA, Castro-Costa E, et al. The Brazilian Longitudinal Study of Aging (ELSI-Brazil): Objectives and Design. Am J Epidemiol. 2018;187(7):1345-53. 
23. Celeste RK, Bastos JL. Mid-point for open-ended income category and the effect of equivalence scales on the income-health relationship. Rev Saude Publica. 2013;47 Suppl 3:16871.

24. Castro-Costa E, Lima-Costa MF, Andrade FB, Souza Junior PRB, Ferri CP. Cognitive function among older adults: ELSI-Brazil results. Rev Saude Publica. 2018;52Suppl 2(Suppl 2):4s. 25. Batistoni SST, Néri AL, Cupertino AP. Validity and reliability of the Brazilian version of the Center for Epidemiological Scale - Depression (CES-D) in Brazilian elderly

Validade e confiabilidade da versão Brasileira da Center for Epidemiological Scale - Depression (CES-D) em idosos Brasileiros. Psico-USF. 2010;15(1):13-22.

26. Turvey $\mathrm{CL}$, Wallace RB, Herzog R. A revised CES-D measure of depressive symptoms and a DSM-based measure of major depressive episodes in the elderly. Int Psychogeriatr. 1999;11(2):139-48.

27. von Elm E, Altman DG, Egger M, Pocock SJ, Gotzsche PC, Vandenbroucke JP, et al. The Strengthening the Reporting of Observational Studies in Epidemiology (STROBE) Statement: Guidelines for reporting observational studies. Int J Surgery. 2014;12(12):1495-9.

28. Blinder AS. Wage discimination: Reduced form and structural estimates. J Hum Resour. 1973;8:436-55.

29. Oaxaca R. Male-female wage differentials in urban labor markets. Int Economic Rev. 1973;14:693-709.

30. Newmark D. Employers' discriminatory behavior and the estimation of wage discrimination. J Hum Resour. 1988;23:279-95.

31. Stata 2015 v.14 (College Station, Texas, EUA)

32. Lutfiyya MN, Gross AJ, Soffe B, Lipsky MS. Dental care utilization: examining the associations between health services deficits and not having a dental visit in past 12 months. BMC public health. 2019;19(1):265.

33. Yoon H, Jang Y, Choi K, Kim H. Preventive Dental Care Utilization in Asian Americans in Austin, Texas: Does Neighborhood Matter? Int J Environ Res Public Health. 2018;15(10). pii: E2261.

34. Jang Y, Yoon H, Rhee M-K, Park NS, Chiriboga DA, Kim MT. Factors associated with dental service use of older Korean Americans. Community Dent Oral Epidemiol. 2019;47(4):340-5.

35. Sabbah W, Tsakos G, Sheiham A, Watt RG. The effects of income and education on ethnic differences in oral health: a study in US adults. J Epidemiol Community Health. 2009;63(7):51620.

36. Deguchi M, Mau M, Davis J, Niederman R. Preventable Tooth Loss in Hawai'i: The Role of Socioeconomic Status, Diabetes, and Dental Visits. Prev Chronic Dis. 2017;14. :E115

37. Ribeiro CG, Cascaes AM, Silva AER, Seerig LM, Nascimento GG, Demarco FF. Edentulism, Severe Tooth Loss and Lack of Functional Dentition in Elders: A Study in Southern Brazil. Braz dent J. 2016;27(3):345-52.

38. Bomfim RA, Frias AC, Cascaes AM, Pereira AC. Functional dentition and associated factors in Brazilian elderly people: A multilevel generalised structural equation modelling approach. Gerodontology. 2018;35(4):350-8.

39. Phelan JC, Link BG. Is Racism a Fundamental Cause of Inequalities in Health?Annu. Rev. Sociol. 2015.41:311-330

40. Naorungroj S, Schoenbach VJ, Wruck L, Mosley TH, Gottesman RF, Alonso A, et al. Tooth loss, periodontal disease, and cognitive decline in the Atherosclerosis Risk in Communities (ARIC) study. Community Dent Oral Epidemiol. 2015;43(1):47-57.

41. Yoon H, Jang Y, Choi K, Kim H. Preventive Dental Care Utilization in Asian Americans in Austin, Texas: Does Neighborhood Matter?. Int J Environ Res Public Health. 2018;15(10):2261. Published 2018 Oct 16. doi:10.3390/ijerph15102261 
42. Constante HM. Racial inequalities in public dental service utilization: Exploring individual and contextual determinants among middle-aged Brazilian adults [published online ahead of print, 2020 Apr 1]. Community Dent Oral Epidemiol. 2020;10.1111/cdoe.12533. doi:10.1111/cdoe.12533 
Table 1. Descriptive characteristics and weighted proportions. The ELSI study 2015-16

\begin{tabular}{|c|c|c|c|c|}
\hline \multirow[t]{2}{*}{ Individual variables } & \multirow[t]{2}{*}{$\mathrm{n}=7,126$} & \multirow[t]{2}{*}{$\%(95 \% \mathrm{CI})$} & \multirow{2}{*}{$\begin{array}{l}\begin{array}{l}\text { Functional } \\
\text { Dentition ( }>20 \\
\text { teeth) }\end{array} \\
\%(95 \% \mathrm{CI})\end{array}$} & \multirow{2}{*}{$\begin{array}{l}\text { Tooth Loss } \\
\text { mean }(95 \% \mathrm{CI}) \\
\end{array}$} \\
\hline & & & & \\
\hline \multicolumn{5}{|c|}{ Sociodemographic characteristics } \\
\hline \multicolumn{5}{|l|}{ Ethnic group } \\
\hline White & 2,922 & $44.0(38.8 ; 49.3)$ & $37.1(33.5 ; 40.9)$ & $18.7(17.8 ; 19.6)$ \\
\hline Brown & 3,421 & $46.1(41.9 ; 50.3)$ & $28.9(26.4 ; 31.6)$ & $20.4(19.7 ; 21.1)$ \\
\hline Black & 723 & $9.9(8.3 ; 11.9)$ & $30.0(25.1 ; 35.4)$ & $20.7(19.5 ; 22.0)$ \\
\hline \multicolumn{5}{|l|}{ Sex } \\
\hline Female & 4,007 & $53.8(50.4 ; 57.1)$ & $27.5(25.0 ; 30.2)$ & $21.1(20.5 ; 21.8)$ \\
\hline Male & 3,119 & $46.2(42.9 ; 49.6)$ & $38.6(35.7 ; 41.6)$ & $18.0(17.2 ; 18.7)$ \\
\hline \multicolumn{5}{|l|}{ Age Groups } \\
\hline 50 to 59 & 3,216 & $50.6(46.3 ; 54.9)$ & $43.6(40.9 ; 46.4)$ & $16.3(15.6 ; 16.9)$ \\
\hline 60 to 69 & 2,262 & $30.5(28.3 ; 32.7)$ & $25.3(22.2 ; 28.5)$ & $21.7(20.9 ; 22.5)$ \\
\hline 70 to 79 & 1,258 & $14.4(12.5 ; 16.5)$ & $17.0(13.8 ; 20.8)$ & $24.9(24.0 ; 25.9)$ \\
\hline $80+$ & 390 & $4.5(3.7 ; 5.4)$ & $9.0(6.0 ; 13.3)$ & $27.2(26.2 ; 28.1)$ \\
\hline \multicolumn{5}{|c|}{ Per capita income tertiles (US\$ Mean) } \\
\hline Lowest (US\$98.4) & 2,207 & $29.3(25.9 ; 33.0)$ & $26.3(23.4 ; 29.5)$ & $21.3(20.6 ; 21.9)$ \\
\hline Intermediate (US\$239.7) & 2,364 & $32.4(30.7 ; 34.1)$ & $25.4(22.2 ; 28.7)$ & $21.6(20.6 ; 22.6)$ \\
\hline Highest (US\$714.9) & 2,555 & $38.3(34.7 ; 42.0)$ & $43.6(40.3 ; 47.0)$ & $16.8(16.0 ; 17.6)$ \\
\hline \multicolumn{5}{|l|}{ Schooling years } \\
\hline 0 & 953 & $10.7(8.7 ; 13.1)$ & $10.9(8.3 ; 14.2)$ & $25.8(25.0 ; 26.6)$ \\
\hline 1 to 4 & 1,398 & $18.1(16.4 ; 19.8)$ & $14.7(12.5 ; 17.2)$ & $24.6(23.9 ; 25.2)$ \\
\hline 4 to 7 & 2,172 & $31.0(29.1 ; 33.0)$ & $25.9(23.4 ; 28.6)$ & $21.4(20.8 ; 22.0)$ \\
\hline 7 to 11 & 857 & $12.9(11.5 ; 14.4)$ & $40.1(34.7 ; 45.7)$ & $17.5(16.1 ; 18.9)$ \\
\hline $12+$ & 1,746 & $27.3(25.0 ; 29.7)$ & $57.1(53.4 ; 60.7)$ & $13.1(12.3 ; 13.9)$ \\
\hline \multicolumn{5}{|l|}{ Medical conditions } \\
\hline \multicolumn{5}{|l|}{ Hypertension } \\
\hline Yes & 3,755 & $51.3(49.3 ; 53.3)$ & $27.8(25.3 ; 30.5)$ & $21.0(20.3 ; 21.6)$ \\
\hline No & 3,371 & $48.7(46.7 ; 50.7)$ & $37.7(34.7 ; 40.9)$ & $18.3(17.5 ; 19.1)$ \\
\hline \multicolumn{5}{|l|}{ Depressive symptoms } \\
\hline Yes ( $\geq 4$ symptoms) & 2,431 & $32.9(31.2 ; 34.6)$ & $25.7(22.7 ; 22.8)$ & $21.4(20.6 ; 22.1)$ \\
\hline No & 4,695 & $67.1(65.4 ; 68.8)$ & $36.1(33.3 ; 38.9)$ & $18.8(18.1 ; 19.6)$ \\
\hline \multicolumn{5}{|c|}{ Cognition (memory score tertiles) } \\
\hline Lowest memory score & 2,914 & $38.3(35.7 ; 40.9)$ & $22.1(19.5 ; 24.9)$ & $22.9(22.2 ; 23.5)$ \\
\hline $2^{\text {nd }}$ and highest tertiles & 4,212 & $61.7(59.1 ; 64.3)$ & $39.2(36.5 ; 41.9)$ & $17.7(17.0 ; 18.3)$ \\
\hline \multicolumn{5}{|l|}{ Diabetes } \\
\hline Yes & 1,122 & $14.4(14.1 ; 16.9)$ & $28.4(24.7 ; 32.5)$ & $21.0(19.9 ; 22.1)$ \\
\hline No & 6,004 & $84.6(83.1 ; 85.9)$ & $33.4(30.8 ; 36.1)$ & $19.4(18.8 ; 20.1)$ \\
\hline \multicolumn{5}{|l|}{ Smoking status } \\
\hline Never smoked & 3,249 & $45.6(44.0 ; 47.2)$ & $38.1(34.8 ; 41.5)$ & $18.3(17.4 ; 19.2)$ \\
\hline Smoked in the past & 2,670 & $37.0(35.1 ; 39.0)$ & $28.8(26.0 ; 31.8)$ & $20.5(19.8 ; 21.2)$ \\
\hline Current smoker & 1,207 & $17.3(16.0 ; 18.8)$ & $26.5(22.9 ; 30.5)$ & $21.4(20.5 ; 22.3)$ \\
\hline
\end{tabular}

Dental visit in the past 12 months 


\begin{tabular}{lcccc} 
Yes & 2,375 & $35.0(33.0 ; 37.1)$ & $47.3(44.5 ; 50.3)$ & $15.4(14.8 ; 16.0)$ \\
No & 4,751 & $65.0(62.9 ; 67.0)$ & $24.7(21.9 ; 27.7)$ & $22.0(21.2 ; 22.7)$ \\
Dental visits for check-up/prevention only & & & & \\
Yes & 1,547 & $23.3(21.3 ; 25.5)$ & $45.1(41.1 ; 49.2)$ & $16.1(15.1 ; 17.0)$ \\
No & 5,579 & $76.7(74.5 ; 78.7)$ & $28.8(26.4 ; 31.5)$ & $20.7(20.1 ; 21.4)$ \\
\hline $95 \%$ CI: 95\% confidence intervals & & & &
\end{tabular}


Table 2. Logistic regression coefficients for racial inequalities in functional dentition by age groups. ELSI 2015-2016

\begin{tabular}{|c|c|c|c|c|c|c|}
\hline \multirow{3}{*}{ Covariates } & \multicolumn{2}{|c|}{50 to 59 years $(n=3,216)$} & \multicolumn{2}{|c|}{60 to 69 years $(n=2,262)$} & \multicolumn{2}{|c|}{70 to 79 years $(n=1,258)$} \\
\hline & $\begin{array}{l}\text { Unadjusted } \\
\text { OR (95\%CI) }\end{array}$ & $\begin{array}{c}\text { Adjusted* } \\
\text { OR (95\%CI) }\end{array}$ & $\begin{array}{c}\text { Unadjusted } \\
\text { OR (95\%CI) }\end{array}$ & $\begin{array}{c}\text { Adjusted* } \\
\text { OR (95\%CI) }\end{array}$ & $\begin{array}{c}\text { Unadjusted } \\
\text { OR (95\%CI) }\end{array}$ & $\begin{array}{c}\text { Adjusted* } \\
\text { OR (95\%CI) }\end{array}$ \\
\hline & \multicolumn{2}{|c|}{ prevalence $43.6 \%$} & \multicolumn{2}{|c|}{ prevalence $25.3 \%$} & \multicolumn{2}{|c|}{ prevalence $17.0 \%$} \\
\hline \multicolumn{7}{|l|}{ Ethnic } \\
\hline White & 1 & 1 & 1 & 1 & 1 & 1 \\
\hline Blacks & $1.31(0.90 ; 1.93)$ & $0.93(0.61 ; 1.42)$ & $1.55(1.02 ; 2.34)$ & $1.05(0.66 ; 1.68)$ & $1.49(0.46 ; 4.81)$ & $0.93(0.23 ; 3.74)$ \\
\hline Browns & $1.44(1.19 ; 1.74)$ & $1.16(0.96 ; 1.41)$ & $1.83(1.36 ; 2.48)$ & $1.15(0.85 ; 1.66)$ & $2.04(1.24 ; 3.33)$ & $1.89(1.17 ; 3.04)$ \\
\hline \multicolumn{7}{|l|}{ Income } \\
\hline lowest & 1 & 1 & 1 & 1 & 1 & 1 \\
\hline middle & $0.87(0.69 ; 1.09)$ & $1.14(0.89 ; 1.46)$ & $0.82(0.56 ; 1.21)$ & $0.78(0.53 ; 1.14)$ & $1.36(0.66 ; 2.79)$ & $1.36(0.70 ; 2.65)$ \\
\hline upper & $0.44(0.34 ; 0.56)$ & $0.89(0.69 ; 1.16)$ & $0.26(0.19 ; 0.36)$ & $0.53(0.37 ; 0.78)$ & $0.41(0.20 ; 0.83)$ & $0.79(0.43 ; 1.45)$ \\
\hline \multicolumn{7}{|l|}{ Schooling } \\
\hline 0 & 1 & 1 & 1 & 1 & 1 & 1 \\
\hline under 4 & $0.68(0.42 ; 1.08)$ & $0.79(0.48 ; 1.26)$ & $1.16(0.61 ; 2.21)$ & $1.47(0.76 ; 2.84)$ & $1.00(0.50 ; 1.96)$ & $1.31(0.67 ; 2.56)$ \\
\hline 4 to 7 & $0.45(0.28 ; 0.71)$ & $0.59(0.37 ; 0.93)$ & $0.44(0.28 ; 0.69)$ & $0.67(0.43 ; 1.04)$ & $0.45(0.22 ; 0.91)$ & $0.74(0.40 ; 1.38)$ \\
\hline 7 to 11 & $0.24(0.15 ; 0.38)$ & $0.33(0.20 ; 0.55)$ & $0.26(0.15 ; 0.45)$ & $0.43(0.24 ; 0.74)$ & $0.36(0.13 ; 0.94)$ & $0.69(0.28 ; 1.67)$ \\
\hline above 11 & $0.13(0.08 ; 0.21)$ & $0.22(0.13 ; 0.35)$ & $0.11(0.07 ; 0.17)$ & $0.25(0.15 ; 0.40)$ & $0.11(0.05 ; 0.22)$ & $0.25(0.12 ; 0.48)$ \\
\hline
\end{tabular}

*Adjusted for dental visits in the past year, check-ups visits, income, schooling years and smoking status. 
Table 3. Proportion of ethnic inequality in tooth loss and natural teeth categories explained by associated factors and adjusted for age-groups. ELSI study 2015-16.

\begin{tabular}{|c|c|c|c|c|}
\hline \multirow[b]{2}{*}{ Mean tooth loss Non-Whites } & \multicolumn{2}{|l|}{ Tooth Loss } & \multicolumn{2}{|c|}{ Natural Teeth categories** } \\
\hline & 20.4 & & $\begin{array}{l}\text { Mean Dentition } \\
\text { Whites }\end{array}$ & 1.7 \\
\hline Mean tooth loss Whites & 18.7 & & $\begin{array}{l}\text { Mean Dentition Non- } \\
\text { Whites }\end{array}$ & 1.5 \\
\hline Characteristics & Explained (Neumark) & $\begin{array}{l}\text { Proportion } \\
\text { explained } \\
(\%) \\
\end{array}$ & Explained (Neumark) & $\begin{array}{c}\text { Proportion } \\
\text { explained } \\
(\%)\end{array}$ \\
\hline Total & $1.2(0.7,1.8)$ & 70.5 & $0.13(0.06 .0 .19)$ & 77 \\
\hline \multicolumn{5}{|l|}{ Explanatory Variables } \\
\hline Dental visits less 1 year & $0.289(0.163,0.416)$ & 23.3 & $0.035(0.020,0.050)$ & 26.5 \\
\hline Check-up dental visits & $0.192(0.098,0.287)$ & 15.5 & $0.017(0.008,0.026)$ & 12.9 \\
\hline Age groups & $-0.37(-0.603,-0.127)$ & -29.8 & $-0.04(-0.066 /-0.013)$ & -29.5 \\
\hline Smoke & $0.087(0.010,0.165)$ & 7.0 & $0.009(0.001,0.017)$ & 7.6 \\
\hline Schooling & $0.436(0.290,0.582)$ & 35.2 & $0.048(0.031,0.063)$ & 34.1 \\
\hline Income & $0.411(0.235,0.587)$ & 33.1 & $0.04(0.020,0.060)$ & 27.3 \\
\hline Cognition & $0.126(0.055,0.197)$ & 10.2 & $0.013(0.005,0.020)$ & 9.1 \\
\hline Depressive symptoms & $0.04(-0.006,0.086)$ & 3.2 & $0.003(-0.001,0.007)$ & 2.3 \\
\hline Hypertension & $0.028(-0.006,0.062)$ & 2.3 & $0.002(-0.001,0.005)$ & 1.5 \\
\hline Diabetes & $0.00(-0.015,0.007)$ & 0.4 & $0.00(-0.012,0.014)$ & 0 \\
\hline Female & $0.007(-0.120,0.135)$ & 0.6 & $0.00(-0.001,0.001)$ & 0 \\
\hline $\begin{array}{l}\text { Smoking status and use of dental } \\
\text { services explained } *\end{array}$ & 45.8 & & & 47.7 \\
\hline Unexplained & 0.5 & 29.5 & 0.04 & 23 \\
\hline Difference & 1.7 & & 0.17 & \\
\hline
\end{tabular}

*Smoking status, dental visits and dental check-ups

**Sensitivity analysis, according to teeth categories: edentulous, 1-9 teeth, 10-19 teeth and more than 20 teeth. 
Table 4. Proportion of ethnic inequality in tooth loss explained by associated factors and age group. The ELSI study 2015-16.

\begin{tabular}{|c|c|c|c|c|c|c|}
\hline & \multicolumn{6}{|c|}{ Tooth Loss } \\
\hline & \multicolumn{2}{|c|}{$50-59$ years $(n=3,216)$} & \multicolumn{2}{|c|}{$60-69$ years $(n=2,262)$} & \multicolumn{2}{|c|}{$70-79$ years $(n=1,258)$} \\
\hline $\begin{array}{l}\text { Mean tooth loss in } \\
\text { Black/Browns }\end{array}$ & 17.2 & & 22.8 & & 25.8 & \\
\hline Mean tooth loss in Whites & 15.0 & & 20.3 & & 24.0 & \\
\hline Characteristics & $\begin{array}{c}\text { Explained Neumark } \\
(95 \% \mathrm{CI})\end{array}$ & $\begin{array}{c}\text { Proportion } \\
\text { explained } \\
(\%)\end{array}$ & $\begin{array}{c}\text { Explained Neumark } \\
(95 \% \mathrm{CI})\end{array}$ & $\begin{array}{l}\text { Proportion } \\
\text { explained } \\
(\%)\end{array}$ & $\begin{array}{c}\text { Explained Neumark } \\
(95 \% \mathrm{CI})\end{array}$ & $\begin{array}{c}\text { Proportion } \\
\text { explained } \\
(\%)\end{array}$ \\
\hline Total & $1.4(0.9,1.9)$ & 67.0 & $2.3(1.6,3.0)$ & 91.7 & $1.2(0.4,2.0)$ & 69.0 \\
\hline \multicolumn{7}{|l|}{ Explanatory Variables } \\
\hline Dental visits in the past year & $0.294(0.115,0.474)$ & 20.7 & $0.398(0.153,0.643)$ & 17.2 & $0.167(-0.248,0.582)$ & 13.9 \\
\hline Check-up dental visits & $0.202(0.079,0.326)$ & 14.2 & $0.248(0.073,0.421)$ & 10.7 & $0.066(-0.089,0.221)$ & 5.5 \\
\hline Smoking status & $0.078(-0.038,0.187)$ & 5.5 & $0.055(-0.057,0.163)$ & 2.4 & $0.036(-0.090,0.163)$ & 3.0 \\
\hline Schooling years & $0.360(0.196,0.523)$ & 25.4 & $0.644(0.363,0.927)$ & 27.9 & $0.346(0.123,0.570)$ & 28.8 \\
\hline Income & $0.310(0.053,0.568)$ & 21.8 & $0.644(0.348,0.941)$ & 27.9 & $0.301(0.065,0.539)$ & 25.1 \\
\hline Cognition & $0.138(0.040,0.237)$ & 9.7 & $0.181(0.009,0.353)$ & 7.8 & $0.167(-0.009,0.343)$ & 13.9 \\
\hline Depressive symptoms & $0.011(-0.040,0.062)$ & 0.8 & $0.091(-0.042,0.225)$ & 3.9 & $0.041(-0.074,0.157)$ & 3.4 \\
\hline Hypertension & $0.062(-0.018,0.141)$ & 4.4 & $-0.013(-0.059,0.034)$ & -0.6 & $-0.031(0.128,0.064)$ & -2.6 \\
\hline Female & $-0.036(0.012,0.139)$ & -2.5 & $0.053(-0.119,0.224)$ & 2.3 & $0.117(-0.123,0.358)$ & 9.8 \\
\hline Diabetes & $0.002(-0.035,0.038)$ & 0.1 & $0.009(-0.020,0.039)$ & 0.4 & $-0.009(0.053,0.036)$ & -0.8 \\
\hline $\begin{array}{l}\text { Smoking status and use of } \\
\text { dental services explained } \\
(\%)^{*}\end{array}$ & & 40.4 & & 30.3 & & 22.4 \\
\hline Unexplained & $0.7(-0.3,1.7)$ & $33.0 \%$ & $0.21(-1.03,1.45)$ & $10.3 \%$ & $0.53(-0.74,1.79)$ & $31.0 \%$ \\
\hline Difference & $2.1(1.1,3.2)$ & & $2.5(1.1,3.9)$ & & $1.8(0.2,3.3)$ & \\
\hline
\end{tabular}

*Smoking status, dental visits and check-up 
